\title{
Association of Pharmaceutical Teachers of India ( APTI ) and Prime Focus on Pharmacy Practice - A need for the Day
}

APTI is a body which is always in for the betterment and upliftment of Teaching Profession. The Association has grown with a prime focus on Stability of Teachers Jobs in the Profession. The teachers training Centre of APTI is on the Anvil. Various modules in collaboration with the Universities is on to develop the Teaching Learning Process further. We all are keen to develop and strengthen the scientific base of Teachers. The journals of repute IJPER and IJOPP published by APTI are of high value with Impact Factor. There is a Bulletin to share our professional acclaims and achievements. The conventions held every year in India and Abroad are a forum for teachers to express and exchange their views. In the glittering ceremony awards are given to teachers and they are recognized for their achievements.APTI has lots in store and is working hard to have a cumulative approach for the profession where teachers are the major contributors.

Indian Journal of Pharmacy under the able editorship of Dr. Shobha Rani RH and the new entrant editors Dr. Ramjan and Mrs. Rajeshwari are doing exceptionally well. The Revised team with new responsibilities is listed in the Journal Editorial Team. There is going to be an invited article in every issue. There will be more focus on Pharmacy Practice in India and Abroad. The Journal will also create forum for Scientific exchange and for Job opportunities. There will be live channels for Further studies, Grants and scope around the Globe.

There is immense need to have Pharmacovigilance centres in all the Hospitals and Health Care Units.

WHO defines pharmacovigilance as the science and activities relating to the detection, assessment, understanding and prevention of adverse effects or any other medicine-related problem.

Pharmacovigilance is an important and integral part of clinical research. Both clinical trials safety and post marketing pharmacovigilance are critical throughout the product life cycle. With a number of recent high-profile drug withdrawals, the pharmaceutical industry and regulatory agencies have raised the bar. Early detection of signals from both clinical trials and post marketing surveillance studies have now been adapted by major pharmaceutical companies in order to identify the risks associated with the medicinal product and effectively managing the risks by applying robust risk management plans throughout the life cycle of the product.e

Pharmacovigilance is still in its infancy in India and there exists limited knowledge about the discipline. While major advancements of the discipline of pharmacovigilance have taken place in the Western countries, not much has been achieved in India. However, with more and more clinical trials and other clinical research activities being conducted in India, there is an immense need to understand the importance of pharmacovigilance and how it impacts the life cycle of the product. This will enable integration of good pharmacovigilance practice in the processes and procedures to help ensure regulatory compliance and enhance clinical trial safety and post marketing surveillance. A very important contribution that a well-established Pharmacovigilance system can provide is the possibility of identifying the potential for using the ADR data to develop new indications and uses for a drug marketed for a specific indication. There are a number of cases where the observation of a side effect has led to the development of a new indication for an existing drug.

with Best wishes and Regards,

Dr. Raman DANG

Secretary APTI

DOI: $10.5530 /$ ijopp.10.1.1 